\title{
Transforming a Small and Medium Enterprise (SME) into an Enterprise Beyond SME level: A Case Study of Mwaiteka Investment
}

\author{
Article by Ernest Mubita \\ Management, Texila American University \\ E-mail: ernestmubita@gmail.com
}

\begin{abstract}
The SMEs are spread across the country and their social-economic contributions to the communities in which they are found cannot be ignored. Mwaiteka Investment, an enterprise where the study was carried out, is one of these SMEs that are found in Kabwe, Zambia. This enterprise has been in business for over 18 years and has not grown, a situation which has brought a lot of concerns and hence the need for this study to find out why the enterprise has not achieved any growth.

The stagnation in growth of the enterprise is a big challenge which needs to be addressed because of the enterprise's contribution to the national development. If this challenge is addressed the enterprise will reduce the unemployment and poverty levels further in the country and also contribute more to the national treasury.

The study collected data using research tools such as interviews, observations and data from enterprise's records. The data was analysed using descriptive analysis and the study then came up with findings, and conclusions. Some of the findings from the study indicated that poor entrepreneurial and enterprise culture, inadequate resources, lack of credit facilities, lack of skilled and experienced manpower, Business Development Services (BDS) programmes too expensive were some of the factors which could have contributed to challenges the enterprise was facing.
\end{abstract}

Keywords: SMEs, Innovation, Growth, Culture.

\section{Introduction and background information}

Zambia is a developing country like many other African countries; its economy before 1991 was mostly controlled by the government which owned parastatel companies. The parastatel companies were not performing well and the government decided to change the way the economy of the country was being managed and in 1991 the government liberalised the economy. The liberalisation resulted in most of the state-owned companies being privatised.

In supporting the creation of small-scale enterprises, the government of Zambia enacted the Small Enterprise Development Act in 1996.The act led to the creation of the Small Enterprise Development Board (SEDB) which was mandated to promote and facilitate the creation and development of micro and small enterprises in the country. Arising from the act, the government came up with policies that were to stimulate and encourage the creation of small and medium enterprises (SMEs) which the government embraced as partners and the most preferred route to alleviate poverty in the country and delivering the most needed economic growth to all parts of the country. Over the years the government has put a lot of emphasis on the development of small and medium scale enterprises and it recognised the importance of the SMEs in the creation of employment and poverty alleviation. The enabling environment that the government has created for the formation of these small enterprises has seen many enterprises being set up. These enterprises have been playing a very important role in the economic development of the country. The Zambian government attaches a lot of commitment to the wellbeing and growth of this sector considering their massive contributions in job creation and poverty alleviation. Small and Medium Enterprises (SMEs) cut across all sectors of the economy and provide the muchneeded employment, not to mention the breeding ground for medium and large industries, which are critical for the national development.

Despite the government's efforts and support it has been giving to the sector, the growth of these SMEs has not been impressive and most of them have reached a stage where further growth is not likely to take place unless other hindering factors are identified. The Zambian government has created an 
enabling environment for the creation of these enterprises in response to the recommendations that were made by International Labour Organisation (ILO) conference of 1998. The conference stressed on the importance of member states coming up with a policy framework that encouraged the creation of an environment that was conducive for this particular sector (ILO website).

This sector still faces a lot of challenges due to the liberalisation of economy and globalisation. The SMEs are under intensive pressure from the established and international companies and are therefore subjected to international competition. The policies that were put in place in the early 1990s opened up the country's internal markets and exposed these SMEs to this competition. There is need therefore in the country to revisit some of the policies and come up with appropriate policies and strategies that will stimulate the growth of SMEs and enable them to compete with these companies. Lack of appropriate policies and other support services that target the SMEs might have affected the growth of this sector and their survival in a competitive environment.

This research was carried out at Mwaiteka Investment an SME based in kabwe, a town that is situated in the central province of Zambia. This company is owned by one entrepreneur and it manufactures steel products such as door frames, Window frames, steel chairs and many other steel products plus construction of steel structures. The enterprise was established in 1994 with two employees and the owner as the director and since then the company has been in operation. The company now has eleven employees plus the director. The biggest challenge that the company has faced since its inception is lack of growth, in that it has not performed very well in terms of expanding its operations and also diversifying.

The research is expected to provide new knowledge in terms of other measures that have not yet been looked at by this particular enterprise. The research topic has aroused interest because everyone in the country would want to see massive contribution of this sector to the national development in terms of reducing unemployment levels and paying taxes. This research therefore will focus on transforming a stagnant Mwaiteka Investment, an SME, into an enterprise that can grow beyond SME level.

\section{Statement of the problem}

The problem which this study wishes to address is the transformation of a stagnant Mwaiteka Investment, an SME situated in Kabwe town, into an enterprise that can grow beyond SME level. The contribution of Mwaiteka Investment to the national development was supposed to be very high in terms of creating jobs and poverty eradication. There have been some efforts to address the development of the SMEs and their growth to other levels by the government and other stakeholders but that had not been achieved fully and Mwaiteka enterprise was one of those enterprises that had not benefited much from the government and other stakeholders.

Kabwe town was once a mining town that used to contribute massively to the economic development of the country. The town was well known for being the only mine for Zinc and lead in the country. The mine was closed in 1994 when it was felt that there were no more Zinc and Lead deposits to mine. The town became a "ghost town" as it was popularly being referred to by the citizens. It earned that name because all the social and economic activities in the town were badly affected by the closure. The mine was a major employer in the whole province and Kabwe in particular. It was after the closure of the mine that some of the former employees of the mine became entrepreneurs and opened up enterprises. It is these entrepreneurs that have managed to rekindle the town once more. Kabwe is no longer a ghost town but a town with a lot of SMEs that are contributing to the economic development of the country.

Mwaiteka investment was one of those SMEs which were established after the closure of the mine in Kabwe. The enterprise has not grown much from SME level since its inception in 1994 despite the much-purported efforts by the government and other stakeholders to make the SMEs grow.

There are a number of factors that affected the growth of Mwaiteka Investment, these included work culture, the skill levels of the employees, the management of the enterprise, marketing skills, capitalization- the ease with which the enterprise was able to access capital, networking, provision of business development services (BDS) and strategic planning. If these factors were tackled well, they will eventually influence the size of the enterprise in terms of increase in employees, sales, assets, and profits as well. Mwaiteka Investment just like any other SMEs has great potential to contribute to the economic development of the country if it was harnessed well. 


\section{The role of mwaiteka investment in the national development}

In a developing country like Zambia, the role of an SME like Mwaiteka Investment is enormous. Apart from manufacturing and supplying metal products to customers, it has empowered some Kabwe residents by offering employment to some of them. The number of employees may look small but they look after many family members, on average six (6) family members per employee. The enterprise contributes to the economic development of Kabwe town and the country as a whole.

The most interesting element about Mwaiteka Investment is that it is located within Kabwe and apart from creating employment for the local people it has also assisted the employees and the Director/Owner to eradicate poverty. The contribution of the enterprise in Kabwe town is great and could be summarised as follows:

i. $\quad$ Created employment

ii. $\quad$ Pay taxes to the local authority

iii. Provide the service within town

iv. Poverty eradication for the employees and their family members

v. Economic empowerment of the Director/Owner and employees who are Kabwe residents.

The above benefits have contributed to the economic activities of Kabwe town that have gone up after the closure of Kabwe Mine in 1994. When the economy of the town picked up many people were empowered economically. This is also pointed out by Kanyama, (2010), who says when an economy grows it increases economic activities and money increases in the pockets of certain individuals.

\section{Objectives of the study}

The following were the major objectives of this study:

i. To transform the stagnant Mwaiteka Investment into an enterprise that can grow beyond SME level;

ii. To identify the challenges hindering Mwaiteka Investment from growing beyond SME level.

\section{Significance of this study}

The study critically analysed all the factors that influence growth through literature review and also from Mwaiteka Investment as an SME where the research was carried out plus other stakeholders

The findings of this research would very much benefit Mwaiteka Investment, other SMEs that are in similar business, the government, the Non-Governmental Organisations (NGOs) that support SMEs, the aid agencies, the business community and the people at large. These findings would also aid the government and other stakeholders to realign their policies and tackle this particular problem differently by considering some of the recommendations that the research will come up with. The study will also contribute to the existing literature on SMEs in the country.

\section{Limitations and delimitations of the study}

The study was undertaken as an action research and was only carried out at Mwaiteka Investment where the researcher mingled with the director and his employees plus other stakeholders such as customers of Mwaiteka Investment. The researcher was granted permission by the director /owner of the enterprise to visit the enterprise any time he felt like interviewing, chatting, observing and also checking through some records of the enterprise. The researcher during the time of the study became part of the enterprise in the sense that he was like a member of staff in the enterprise.

\section{Literature review}

The review of some of the relevant works so far that have been done by other researchers and authors of books that have added a lot of knowledge to this area of study with much emphasis on the growth of small and medium sized enterprises was carried out.

\section{Growth}

The growth of an enterprise can be defined in terms of number of employees or percentage growth in sales. Graduation of a firm from one level to the next is an indicator for growth.

The increase in the number of employees is an indicator for enterprise growth and it is also used as an 
economic growth indicator (Kirchoff, 1991). For the entrepreneur, growth can serve as an indicator for success and doing well in business. Enterprise growth is usually expressed in terms of growth in sales. According to Shane, (2005), sales growth increases profitability and the likelihood of an initial public offering, as one would expect given the expansion from a small scale to another level. Growth is an important measure to use when assessing the performance of an enterprise. The other measure that can be used to indicate whether an enterprise is performing well is the income which is a surplus of revenue over costs. According to Kanyama, (2010), on small business enterprises, lack of entrepreneurial skills or the ability to seek out opportunities and turn them into profitable businesses has been attributed to be one of the factors that hamper growth of small businesses in Zambia.

Researchers have shown that small businesses have a lot of potential for growth and are able to grow faster than large businesses. This is so because small enterprises can easily adapt to many changes that take place in the economy, technology and social sector. The advantages that small businesses have are that they usually have manageable workforce and it is easy to disseminate information either from the bottom or top.

\section{Growth and diversification}

Entrepreneurs are well known for marking effective strategic decisions in the management of their enterprises. These strategic decisions keep on changing with time as the business grows. When the business is starting entrepreneurs often want to see their businesses survive and they concentrate on providing one product to the customers competently. Entrepreneurs are expected to change their strategies if they succeed during this stage by either developing new products or moving to new markets by expanding business. This expansion of business is known as Diversification. Holt (1992) defines diversification as a process of extending the market to new areas or coming up with new lines of products or services.

\section{Entrepreneurial and enterprise culture}

Culture is defined as values, beliefs, art, morals, customs, attitudes and any other capabilities that people share as members of a particular society. It is everything that influences an individual's thought process. Culture sets checks and balances for individuals on how they should behaviour and thereby enhancing the performance of an enterprise. Some work culture enhance the spirit of hard work while others discourage hard working and the later will make it difficult for the enterprise to register any growth. According to Aldrich, (1990), social and cultural norms have some influence on the employees and enterprise's entrepreneurial activity. For instance, if the attitude of all the members of staff is to achieve maximum sales it will be attained because everyone's behaviour in the enterprise shall be tuned towards achieving that goal. This type of work culture will improve the performance of the enterprise and eventually enhance growth. Timmons and Spinelli (2007) contend that Organisational culture of any enterprise is critical for its growth. The director of the enterprise should encourage entrepreneurial culture within the enterprise so that everyone in the enterprise is creative and innovative and that can be achieved by rewarding the employees who exhibit such skills. Promoting entrepreneurial culture in an enterprise has the potential to enhance performance and growth.

\section{Strategic planning}

Strategic planning provides a road map that will guide the entrepreneur on how the resources shall be utilised. The plan should give strategic objectives that are to be achieved in a specific period of time. In the strategic plan growth strategies should be highlighted so that the focus is directed towards achieving the objectives. It is important for a new venture to come up with strategic plan and focus on growth, failure to plan will lead to the contraction of the enterprise. According to Holt (1992) research has shown that more than half of the small entrepreneurs start their businesses without formal planning a situation which is not good for the SMEs.

Entrepreneurs who adopt a growth strategy also have ventures that grow faster than those that do not adopt a growth strategy (Shane, 2005). According to White and Reynolds, (1996), firms whose founders expected higher sales and employment growth had actual sales and employment growth that were significantly higher than the figures they had when they focussed. 
According to Frese, (2002), psychological strategy process characterised by complete planning, critical point planning, opportunistic, and reactive as well as entrepreneurial orientation (autonomy, innovativeness, competitive aggressiveness, and risk taking) are related to entrepreneurial success.

\section{Previous education and experience}

Formal education is very essential for any entrepreneur to start up business well and succeed because it enables one to understand a lot of issues surrounding the business venture. According to Holt (1992) on the research that was carried out by Jerome A. Katz in 1984 highlighted that 86 percent of entrepreneur who start new businesses have bachelor's degree and about 71 percent who buy exiting businesses have bachelor's degree and the same researcher also found that more that 90 percent in both groups had several years of prior experience. The findings by Katz therefore suggest that most of the successful entrepreneurs were well educated with some experience and not school dropouts.

The failure rate is low when one has prior experience compared to entrepreneurs without any experience. Nyirongo, (2005), contends that most new businesses fail because owners lack prior entrepreneurial experience.

\section{Networking}

Networking can be a stimulant and source of ideas as well as source of valuable contacts with other entrepreneurs. Organised networks can facilitate and accelerate the process of making contacts and finding new business ideas that could be developed into business opportunities that could be fully exploited. Some studies on this subject have also indicated that effective networking among the established entrepreneurs, government coordinating agencies, and other stakeholders, has the potential to stimulate growth and expansion of SMEs in the country. According to Timmons and Spinelli, (2007), networks can be a stimulant and source of new ideas and source of valuable contacts with people who are either in the same business or have some interest in what one is involved in.

\section{Business development services (BDS)}

These are tailor-made services provided to the entrepreneurs. These services include business management, marketing, business trainings amongst others. These services are offered to SMEs with a view of assisting them to run their businesses well and make profit so that they can achieve the muchdesired enterprise growth. According to Committee of Donor Agencies report (2011) BDS is the service that improves the performance of the enterprise, its access to markets and its ability to compete. In most developing countries like Zambia, business development services are usually too expensive for the SMEs because they are expected to pay full price for these services thereby making most of these SMEs not attending these courses. The BDS programmes are supposed to be subsidised so that many SMEs benefit from these services and be able to contribute more to national development. In Zambia these services are mostly offered by private organisations though sometimes the government do organise such programmes but it does not go around the whole country to benefit all SMEs.

\section{Enterprise resources and performance}

According to Barney, (1991), venture resources in the form of capabilities, assets, capital and human resource skills provide competitive advantage and underpin the organisation's performance. In other words, resources are very important factors for an enterprise's performance and growth. Resources are very important to any business venture and must be managed well because they have the potential to assist the enterprise earn more profit. Any business expansion is as a result of proper utilisation of the resources by the owners of the enterprise.

\section{Location of the enterprise}

Location of a business venture is very essential for performance of an enterprise. The business venture should be situated in an area that is quite accessible for all potential customers. This factor is usually ignored by entrepreneurs, though some is due to lack of capital to get good spaces in prime areas. Good location is a stimulant for enterprise growth. According to Scarborough, (2011), the location decision has far-reaching and often long-lasting effects on a small company's future. By choosing the location wisely with customers' and companies' needs in mind the firm can establish an 
important competitive advantage over rivals.

\section{Demands for the products}

The business venture that attracts more customers to buy its products is also expected to increase production or service to march with the demand. Grant, (2000) says that when all factors are equal the increase in demand will increase the price of the products or services. The increase in demand and price will eventually increase the revenue for enterprise which will enable it to expand its operations.

The enterprise should come up with some marketing strategies to inform people about its products or services and why they should buy them. It is only through marketing that the demand for products could increase thereby enabling the enterprise to perform better. Demands are wants for specific products and services backed by an ability to pay (Kotler, 2006).

\section{Marketing}

Marketing is a process of creating and delivering desired goods and services to customers before competitors do so. Most entrepreneurs believe that their products or services could be bought without marketing. Entrepreneurs that do not put a lot of efforts in marketing have ended up failing in business. According to Kotler, (2006), marketing management is the process of planning and executing the conception, pricing, promotion, and distribution of ideas, goods, and services to create exchanges that satisfy individual and organisational goals.

\section{Conceptual model}

The conceptual model shown on figure 2.1 illustrates the relationships that exist between the director / owner's objectives and venture growth. Entrepreneur's desire to pursue growth is in most cases hindered by limited resources and some external factors that an entrepreneur has very little control over them. The objectives and proper utilisation of factors such as entrepreneurial culture, human resource, BDS and other factors have made enterprises succeed in increasing profit, secure bigger market shares, increase sales and the number of employees which are some of the indicators for an enterprise growth. The combination of these activities and factors when managed competently will lead to quality products and services which eventually will enhance customer satisfaction and thereafter bring about the muchdesired enterprise growth.

\section{Conceptual framework}

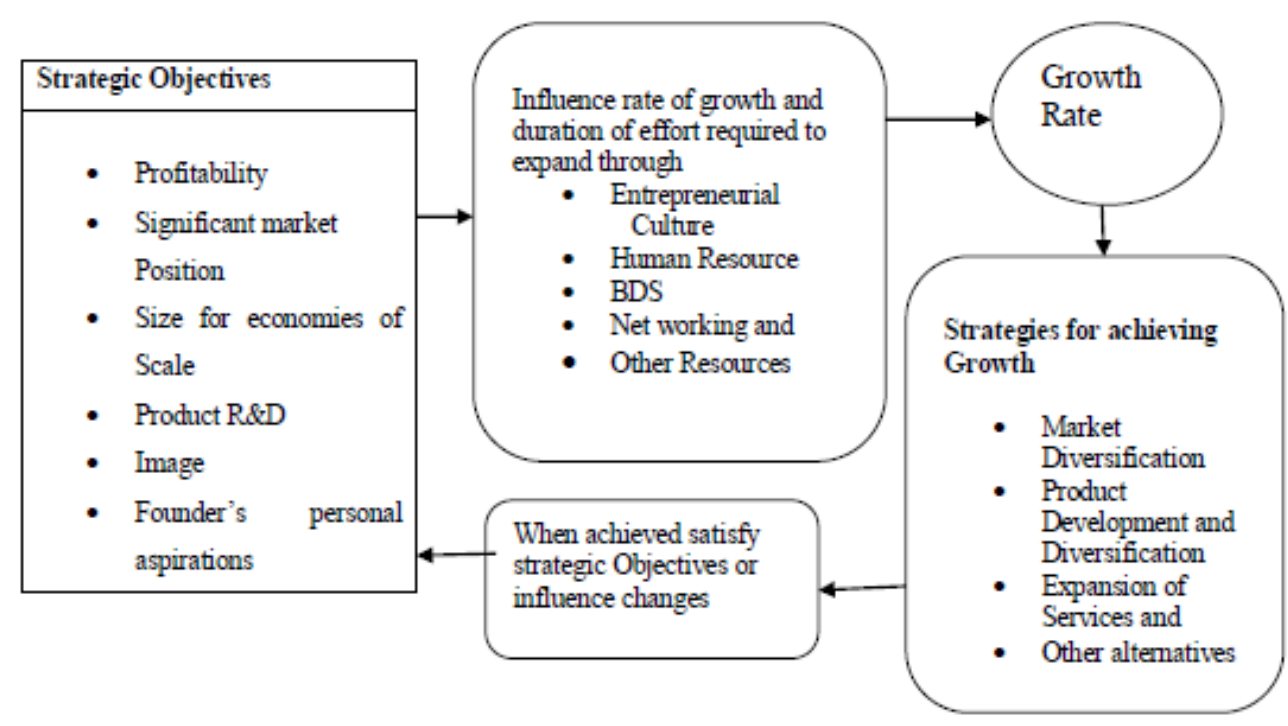

Figure 2.1. The relationship between objectives and venture growth 


\section{Research methodology}

\section{Research design and strategy}

According to Sekaran, (1992), research design means a method of investigation that a scientific research follows in order to come up with anticipated results. This study was basically an action research where both deductive and inductive approaches were exploited. Both approaches were adopted to enable the researcher obtain relevant information concerning the transformation of Mwaiteka investment. The inductive methods were used to gather qualitative information while the deductive approach was used to quantify the responses and enable the researcher make reliable judgements. This study was an action research which was carried out at Mwaiteka Investment.

The action research focussed on solving a particular practical problem at Mwaiteka Investment. According to Stringer, (2007), an action research is a systematic approach to investigation that enables people to find effective solutions to problems they confront in their everyday lives and it focuses on specific situations and offers localised solutions.

The study mainly collected qualitative data, being an action research, which is more inductive in nature and quantitative data also was used though not very much. The data was collected through observations and interviews and others through documents, recording, policies and many other sources such as journals, newspapers and online information. Observation technique, according to Fretching and Sharp, (1997), is a technique by which an individual or individuals gather first-hand data on programmes, process or behaviour being studied. Quantitative data was obtained from documents for instance about the number of employees and educational attainment.

\section{Sample size and sampling procedure}

The sample will be made of 10 stakeholders of Mwaiteka Investment. These will be chosen at random to participate in the research. Purposive sampling method will be used. According to Cohen, (2000), purposive sampling enables a researcher to use cases that will best enable him/her to answer the research question(s) and meet his/her research objectives. And according to Stringer, (2007), Purposeful sampling is that which consciously selects people on the basis of a particular set of attributes.

\section{Data analysis and findings}

The results that were drawn from the analysis provided proper conclusions and recommendations on transforming Mwaiteka investment. In this study, descriptive statistics was used to analyse the data using graphs, tables and percentages.

\section{Research findings (Results)}

The study found out that the enterprise was not diversifying and this strategy could have helped to go round the stiff competition that was being experienced by the firm especially after many other entrepreneurs joined the sector. The director could have looked for new markets that were not yet crowded with entrepreneurs who were offering same products. Apart from searching for new markets he could have come up with completely new products, which could be different from the competitors' products.

The enterprise culture also was found to be one of the factors that were making the enterprise not to perform well. The work culture of the employees was not good. The employees only put in a lot of effort in their day to day jobs when the director was present, the moment he left the workshop most of them became so relaxed that some jobs were never completed on time. That trend has forced some of their customers to move to their competitors where jobs were accompanied within agreed time frame.

Lack of strategic planning was also found to be one of the factors that needed to be addressed. Strategic planning provides vision to the enterprise and the staff. It also sets goals and objectives to be achieved within a specified period. Mwaileka investment did not have a strategic plan a scenario which was not conducive for an enterprise that the owner wanted to register growth in its operations. There was urgent need for the enterprise to come up with some plans that could provide a road map on how it should operate and expand its business. 
Most of the employees of Mwaileka investment were not well educated and had no previous experience in this particular industry. The reasons that were advanced by the director of the enterprise were that educated employees and experienced ones were always demanding for high wages. Due to lack of enough capital the enterprise has continued employing people who were semi-skilled or without any skill. The enterprise has many challenges to retain the staff once they acquired a lot of experience. The enterprise should look for a financial assistance so that it can employ qualified people and retain them in the enterprise. Human resource is very important for any firm that wants to grow.

The business of today is not like the ones that were run by our fore fathers who used to hide their old/poor technology to their competitors. Entrepreneurs of today are expected to create network of enterprises. Mwaiteka investment has few networks with suppliers and few entrepreneurs but there was need for the enterprise to join a big network of entrepreneurs because there are many advantages belonging to such a network. A good network can provide business opportunities to the members of the network.

Mwaiteka investment has survived over years despite the director not having attended many courses that were provided by business development services for entrepreneurs. These courses according to the director are very good for entrepreneurs but very expensive for most of the entrepreneurs like himself. The government should assist entrepreneurs like the director for Mwaiteka investment by subsidising these courses that were being offered to the SMEs. The government should empower entrepreneurs by reducing participation fees for the courses that are meant for entrepreneurs. The director for Mwaiteka investment needs to attend most of these courses so that he could acquire better skills in business management.

The location of Muleteka investment is one area of major concern. The enterprise is situated far from the industrial area and town centre. The enterprise is not easy to locate when you are new in town. The enterprise should be relocated to another area that can easily be accessed by all potential customers. Location of the enterprise has contributed to the firm not registering growth especially that there is stiff competition.

The demand for the products that are manufactured by Mwaiteka Investment is not high. The reasons for the low demand for the product were due to the location of the enterprise and also lack of marketing. The director should market the enterprise together with its products to the general public so that potential customers are informed about its existence. Proper marketing strategies have the capacity to make the enterprise register growth.

Mwaiteka investment should encourage entrepreneurial culture within the enterprise by motivating employees who were creative and innovative. This culture once instilled in the staff increases good performance which enhances enterprise growth.

The director of the enterprise does not want to take high risk opportunities for fearing of losing his money. Risk taking is one of the qualities of a good entrepreneur, and therefore the director should take up high risk opportunities so that the enterprise can start recording some growth. The high risk opportunities have high retains which could accelerate growth.

Mwaiteka investment was linked up to other SMEs in a network that has benefited it very much. The enterprise also was networking well with suppliers of workshop materials. Networking should be encouraged very much even with other stakeholders as the benefits could be enormous for the enterprise.

There were inadequate resources in the enterprise, a situation that has led it to operate without enough capital and outdated machinery/equipment which were unreliable. The other resource that the enterprise was lacking was qualified human resource, the qualified human resource was expensive to employ and retain in an enterprise. The enterprise needed to be assisted with affordable loans so that it could do away with the challenge of inadequate resources. Once that challenge was tackled, the muchdesired growth shall be attained. The unfortunate situation was the loans from Citizen Economic Empowerment Commission (CEEC) which were made cheaper to borrow were characterised with corruption and political interference. The government should remove corrupt officers from the commission and also not to interfere with the way the loans were being given to the deserving entrepreneurs. 


\section{Discussion of the results}

The growth of SMEs should pre-occupy the minds of directors / owners of enterprises, the government and many other stakeholders. The social economic contribution of Mwaiteka Investment in Kabwe town and the country as a whole cannot be ignored. The enterprise has helped to reduce the poverty levels for the director and its employees and in addition it has also reduced the unemployment levels in the town. The study therefore has come up with some recommendations that have been arrived at after a thorough analysis of the research findings and literature review. It is highly hoped that these recommendations will be taken seriously and implemented so that the contribution of this enterprise will be more and the benefits that shall trickle down from it shall benefit a lot of people either directly or indirectly.

Mwaiteka Investment should embrace all its members of staff as part of the enterprise. Entrepreneurial culture is very important in an enterprise as it makes it perform better. Mwaiteka Investment should encourage creativity and innovation among its employees by motivating those who exhibit entrepreneurial skills. On the enterprise culture the enterprise should put in place an induction programme for all its new employees. The employees should always be informed about the preferred work culture when joining the enterprise.

Focusing on enterprise growth requires that all the possible business opportunities are seized. The director should be taking up high risk business opportunities as these have high retains which could propel growth faster.

Networking is one element that has helped many enterprises to perform beyond expected levels because they are able to share technology, ideas and many other things which could add value in the enterprises. Mwaiteka Investment should create networks with other SMEs that have persistently been registering growth in their businesses and also with other stakeholders.

Resources are the drivers of business operations; Mwaiteka Investment therefore should employ qualified and experienced workers who will enable the enterprise to make profit because they are competent.

The enterprise also should send the current employees for staff training and development programmes so that they are well skilled. On the availability of financial resources, the enterprise should take a survey of these financial institutions so that it may find one that lends money with a lower interest rate.

It is not easy for an enterprise to achieve growth without proper investment in machinery / equipment. The enterprise should secure some funds from lending financial institutions to purchase machinery / equipment as these are must for the growth of the enterprise.

On borrowing from CEEC, the enterprise should continue applying for funds and should also engage the services of an expert in writing business plans which is a major criterion that is used by the commission to disburse their funds.

Starting a business venture and managing it successfully depends very much on the level of business management skills that the owner had acquired previously. The director of Mwaiteka Investment should attend business courses that are offered by business development services providers. These courses have the potential to equip the director with the necessary skills required to manage his business venture competently and achieve some growth.

An enterprise that is situated in a good area is capable of scoring a lot of successes. The location of the enterprise has a strong influence on its performance. The director of Mwaiteka Investment relocates the enterprise to a most accessible and central place where it can easily be reached by potential customers.

Mwaiteka Investment is one of the SMEs that have existed for over twenty years that manufacture metal products in Kabwe. Despite having been in business for many years most of the Kabwe residents do not know much about it especially that the situation has been compounded by its bad location resulting in its poor performance. The director should come up with effective marketing strategies which will make the enterprise a household name in metal products and construction in Kabwe and beyond.

Starting a business venture without planning will eventually see the venture failing to survive the pressure that will be exerted by the business environment. Strategic planning is very important as it 
provides the enterprise with vision and goals to achieve. The director together with the employees should come up with a strategic plan which will guide the enterprise.

\section{Conclusions}

The study was based at Mwaiteka Investment an SME based in Kabwe town of Zambia. The enterprise manufactures metal products and also is in the construction business. The enterprise was started by the director/owner in 1994 with only two employees but through the years it has managed to increase its workforce to eleven (11).

The study also has revealed a number of factors that have consistently affected the growth of Mwaiteka Investment and among these the most prominent one is the financial resources. The other ones also are closely related to the financial resources and these are human resource, machinery and entrepreneurial culture. All the foregoing factors appeared to be inadequate in the enterprise and had a lot of negative influence on the growth of the enterprise.

\section{References}

[1]. Barney, j. B (1991) Strategic Human Resource Management, New Delhi, Tata Mcgraw-hll.

[2]. Behr, A.L. (1988) Empirical Research Methods for the Human Sciences $2^{\text {nd }}$ Edition, Durban: Butterworths.

[3]. Burn, P. (2001) Entrepreneurship and Small Business, New York: MacMillan.

[4]. CDAR (2011), Small Enterprise Development.

[5]. Cohen, L. (2000) Research Methods in Education, New York: McGraw-Hill.

[6]. Frese, M. (2002) "Psychological Success Factors of small-Scale businesses in Namibia." Journal of Develomental Entrepreneurship, 7, No. 3, pp. 67-78.

[7]. Finley, L. (1990) Entrepreneurial Strategies: Text and Cases, Boston: Kent Publishing Inc.

[8]. Kanyama, C. (2010) Business Values for Our Time, South Africa: Ultra Litho Pty Limited.

[9]. Khanka, S.S. (2011) Entrepreneurial Development, New Delhi, S. Chad \& Co.Ltd.

[10]. McNiff, J. and Whitehead, J. (2009) Doing and Writing Action Research, London: Sage Publications Ltd.

[11]. Shane, S. (2005) A General Theory of Entrepreneurship, Individual-Opportunity Nexus, Massachusetts: Edward Elgar Publishing Inc.

[12]. Scarborough, N. M. (2011) Essentials of Entrepreneurship and Small Business Management $6^{\text {th }}$ Edition, New Jersey: Pearson Education Inc.

[13]. Saslow, C.A. (1982) Basic Research Methods, New York: McGraw-Hill.

[14]. Sekaran, V. (1992) Research Methods for Business, New York: John Wiley.

[15]. Sekaran, V. (2000) Research Methods for Business-A Skill Building Approach, John Wiley and Sons, New York, USA.

[16]. Small Enterprise Development Act No. 26 of 1996 Zambia Development Agency Act of 2006.

[17]. Stringer, E.T. (2007) Action Research, Third Edition, London: Sage Publication Ltd.

[18]. Tarlor, S.J. and Bogdan, R. (1984) Introduction to Qualitative Research Methods, $2^{\text {nd }}$ Edition, New York: John Wiley.

[19]. TEVET News (2010) Entrepreneurship: Opportunity Seeking and Initiative 8 (1), 8-9.

[20]. Timmons, J. A. And S. Spinelli (2007) New Venture Creation, Entrepreneurship for $21^{\text {st }}$ Centuary, New York: McGraw-hill.

[21]. Wheelen, H, (1992), Strategic Management and Business Policy $4^{\text {th }}$ Edition, Wesley. 